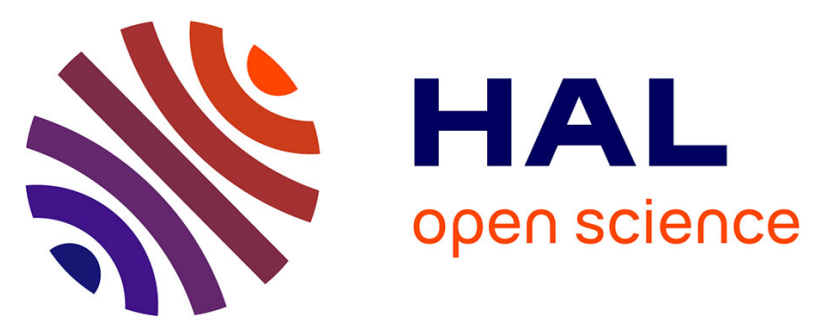

\title{
Elastic anisotropy of polycrystalline Au films: Modeling and respective contributions of X-ray diffraction, nanoindentation and Brillouin light scattering
}

Damien Faurie, Ph Djémia, Éric Le Bourhis, P.O. Renault, Yves E Roussigné, Salim Mourad Cherif, Rénald Brenner, Olivier Castelnau, Gilles Patriarche, Philippe H. Goudeau

\section{To cite this version:}

Damien Faurie, Ph Djémia, Éric Le Bourhis, P.O. Renault, Yves E Roussigné, et al.. Elastic anisotropy of polycrystalline Au films: Modeling and respective contributions of X-ray diffraction, nanoindentation and Brillouin light scattering. Acta Materialia, 2010, Volume 58, Issue 15, pp.4998-5008. 10.1016/j.actamat.2010.05.034 . hal-02156738

\section{HAL Id: hal-02156738 \\ https://hal.science/hal-02156738}

Submitted on 14 Jun 2019

HAL is a multi-disciplinary open access archive for the deposit and dissemination of scientific research documents, whether they are published or not. The documents may come from teaching and research institutions in France or abroad, or from public or private research centers.
L'archive ouverte pluridisciplinaire HAL, est destinée au dépôt et à la diffusion de documents scientifiques de niveau recherche, publiés ou non, émanant des établissements d'enseignement et de recherche français ou étrangers, des laboratoires publics ou privés. 


\title{
Elastic anisotropy of polycrystalline Au films: Modeling and respective contributions of X-ray diffraction, nanoindentation and Brillouin light scattering
}

\author{
D. Faurie ${ }^{\mathrm{a}, *}$, P. Djemia ${ }^{\mathrm{a}}$, E. Le Bourhis ${ }^{\mathrm{b}}$, P.-O. Renault ${ }^{\mathrm{b}}$, Y. Roussigné ${ }^{\mathrm{a}}$, S.M. Chérif ${ }^{\mathrm{a}}$, \\ R. Brenner ${ }^{\mathrm{a}}$, O. Castelnau ${ }^{\mathrm{c}}, \mathrm{G}$. Patriarche ${ }^{\mathrm{d}}, \mathrm{Ph}$. Goudeau ${ }^{\mathrm{b}}$ \\ ${ }^{a}$ Laboratoire des Propriétés Mécaniques et Thermodynamiques des Matériaux (LPMTM), UPR 9001 CNRS, \\ Université Paris-Nord, 93430 Villetaneuse, France \\ ${ }^{\mathrm{b}}$ Institut P', CNRS - Université de Poitiers - ENSMA, UPR 3346, Département de Physique et Mécanique des Matériaux, \\ BP 30179, 86962 Futuroscope, France \\ ${ }^{\mathrm{c}}$ Procédés et Ingénierie en Mécanique et Matériaux (PIMM), ENSAM, 151 Bd de l'Hôpital, 75013 Paris, France \\ ${ }^{\mathrm{d}}$ Laboratoire de Photonique et des Nanostructures (LPN), UPR 20 CNRS, Route de Nozay, 91460 Marcoussis, France
}

Received 18 January 2010; received in revised form 10 May 2010; accepted 16 May 2010

Available online 16 June 2010

\begin{abstract}
Elastic properties of non-textured and $\left\{\begin{array}{lll}1 & 1 & 1\end{array}\right\}$-fiber-textured gold thin films were investigated experimentally by several complementary techniques, namely in situ tensile testing under X-ray diffraction (XRD), nanoindentation and Brillouin light scattering (BLS). Specimens were probed along different directions to reveal the strong effects of elastic anisotropy at the (local) grain and (global) film scales. XRD allows the investigation of both local and global anisotropies, while BLS and nanoindentation are limited to global analyses. A micromechanical model, based on the self-consistent scheme, and accounting for the actual microstructure of the films, is applied to interpret experimental data. Although different types of elastic constants can be determined with the used experimental techniques (static/dynamic, local/ global), a good agreement is obtained, showing that comparison of these techniques is feasible when carried out carefully. In particular, the use of a micromechanical model to estimate the effects of the local elastic anisotropy at the film scale is unavoidable. The presented results show that XRD, BLS and nanoindentation should capture anisotropic texture effects on elastic constants measurements for materials with a Zener anisotropy index larger than 2. Conversely, the actual texture of a given specimen should be taken into account for a proper analysis of elastic constants measurements using those three experimental techniques.
\end{abstract}

(C) 2010 Acta Materialia Inc. Published by Elsevier Ltd. All rights reserved.

Keywords: Brillouin scattering; Nanoindentation; Elastic behavior; X-ray diffraction (XRD); Thin films

\section{Introduction}

Mechanical properties of thin films have received considerable attention because of their length-scale dependence and their implications on the reliable operation of microelectronic and microelectromechanical systems [1-5]. Decreasing the size of structures implies a control of elaboration processes at very small scales. Small dimen-

\footnotetext{
* Corresponding author. Tel.: +33 149403469.

E-mail address: faurie@univ-paris13.fr (D. Faurie).
}

sions, interfaces and singular structures are intrinsic features of thin films [6]. Thus, in parallel to the ongoing efforts to reduce characteristic sizes in microsystems, the study of the mechanical properties at small scales, and of the related size effects, is crucial.

Polycrystalline constants such as Young's, shear and bulk moduli and Poisson's ratio are the typical constants used to characterize most engineering materials and are often useful parameters in engineering design. Among all material properties, Young's modulus is one of the most influential factors in thin-film technological applications. 
Therefore, many techniques have been developed to evaluate its value for small structures, including nanoindentation [7], microbeam bending [8], bulge test $[9,10]$, microtensile $[11,12]$, acoustic microscopy $[13,14]$, picosecond ultrasonics $[15,16]$, Brillouin light scattering (BLS) [17], and in situ tensile testing under X-ray diffraction (XRD) [18] while combined global approaches have been proposed [19]. However, principles and physical background are inherent to each technique. Particularly, the mechanical testing probe directions are dissimilar (in-plane for tensile testing, out of plane for nanoindentation), so that the measured elastic modulus (macroscopic elastic constants) is to be analyzed in view of the grain crystallographic texture and microstructure of thin films locally elastically anisotropic.

Gold single crystals with a face-centered-cubic (fcc) lattice structure exhibit a strong local elastic anisotropy. As for many fcc (metallic) materials, $\langle h h h\rangle$ - and $\langle h 00\rangle$-type directions are respectively the stiffest and the most compliant, with a Young's modulus ratio of about 2.8.

Polycrystalline thin films elaborated by sputtering methods generally show crystallographic textures that can be very pronounced. A $\left\{\begin{array}{llll}1 & 1 & 1\end{array}\right\}$ fiber texture is often encountered in the case of fcc materials [20]. For materials exhibiting an anisotropy of elastic properties at the grain (or local) scale, such as gold, crystallographic textures induce a macroscopic elastic anisotropy whose amplitude increases with the texture strength $[21,22]$ and with the local elastic anisotropy of the grains composing the polycrystalline thin films. In most cases, macroscopic elastic anisotropy is very elevated and cannot be neglected $[23,24]$.

In this paper, we report a study of elastic properties of non-textured and $\left\{\begin{array}{lll}1 & 1 & 1\end{array}\right\}$ fiber-textured gold thin films by in situ tensile testing under XRD, nanoindentation and BLS. Due to the correlation between intrinsic elasticity of thin film and physical experimental probe, the experimental measurements can reveal the crystallographic texture of polycrystalline thin films. We first introduce the general framework of the theoretical model based on a micromechanical approach, as the effect of texture on the effective (or global) elastic constants of the locally anisotropic polycrystalline film needs to be described. Then, after describing the microstructure of gold thin films, we present experimental results from XRD, BLS, and nanoindentation. We finally discuss how these techniques compare with each other, emphasizing the capability of the techniques to capture microstructural effects which, in turn, must be taken into account for a proper analysis of global (macroscopic) elastic anisotropy.

\section{Estimate of polycrystals elastic constants}

The calculation of polycrystalline material elastic constants from single-crystal constants is a complex problem involving the complete distribution of crystalline orientations in the orientation space (crystallographic texture generally measured by XRD) and the spatial distribution of the individual grains as well as their shape. Due to the single-crystal elastic anisotropy, elastic interactions take place within the polycrystal and induce heterogeneous stress and strain fields upon macroscopic loading at the specimen scale. At the local scale, the constitutive law is the generalized Hooke's law which reads:

$\sigma_{\mathrm{ij}}=C_{\mathrm{ijk} 1} \varepsilon_{\mathrm{kl}}$

and

$\varepsilon_{\mathrm{ij}}=S_{\mathrm{ijk} 1} \sigma_{\mathrm{kl}}$

where $\boldsymbol{\sigma}$ and $\boldsymbol{\varepsilon}$ are the stress and strain tensors respectively (with components $\sigma_{\mathrm{ij}}$ and $\varepsilon_{\mathrm{ij}}$ ), and $\mathbf{C}$ and $\mathbf{S}$ the single-crystal stiffness and compliance tensors (with components $C_{\mathrm{ijkl}}$ and $\left.S_{\mathrm{ijkl}}\right)$. For a cubic symmetry, three independent stiffnesses are $C_{11}, C_{12}$ and $C_{44}$, making use of the standard Voigt notation. At the polycrystal scale, the effective stiffness tensor $\widetilde{\mathbf{C}}$ is defined by

$\bar{\sigma}_{\mathrm{ij}}=\widetilde{C}_{\mathrm{ijk} k} \bar{\varepsilon}_{\mathrm{k} 1}$

with $\bar{\sigma}_{\mathrm{ij}}=\left\langle\sigma_{\mathrm{ij}}\right\rangle$ and $\bar{\varepsilon}_{\mathrm{ij}}=\left\langle\varepsilon_{\mathrm{ij}}\right\rangle$ the macroscopic stress and strain at the polycrystal scale (notation $\langle\cdot\rangle$ indicates an average over the whole polycrystal volume). The effective elastic compliance tensor $\widetilde{\mathbf{S}}$ obeys $\widetilde{\mathbf{S}}=\widetilde{\mathbf{C}}^{-1}$. In the case of a global transverse elastic isotropy, which is attained for $\left\{\begin{array}{lll}1 & 1 & 1\end{array}\right\}$-fiber texture, the effective stiffness tensor is expressed as follows, with five independent coefficients:

$$
\widetilde{\mathbf{C}}=\left(\begin{array}{cccccc}
\widetilde{C}_{11} & \widetilde{C}_{12} & \widetilde{C}_{13} & 0 & 0 & 0 \\
\widetilde{C}_{12} & \widetilde{C}_{11} & \widetilde{C}_{13} & 0 & 0 & 0 \\
\widetilde{C}_{13} & \widetilde{C}_{13} & \widetilde{C}_{33} & 0 & 0 & 0 \\
0 & 0 & 0 & \widetilde{C}_{44} & 0 & 0 \\
0 & 0 & 0 & 0 & \widetilde{C}_{44} & 0 \\
0 & 0 & 0 & 0 & 0 & \widetilde{C}_{66}=\left(\widetilde{C}_{11}-\widetilde{C}_{12}\right) / 2
\end{array}\right)
$$

when expressed in the specimen reference frame $\left(S_{1}, S_{2}, S_{3}\right)$ where $S_{3}$ is the revolution axis. For non-textured polycrystals, macroscopic elastic isotropy is obtained with the following additional relations: $\widetilde{\mathbf{C}}_{11}=\widetilde{\mathbf{C}}_{33}, \quad \widetilde{\mathbf{C}}_{12}=\widetilde{\mathbf{C}}_{13}$, $\widetilde{\mathbf{C}}_{44}=\widetilde{\mathbf{C}}_{66}$.

Polycrystalline materials are made of a collection of grains exhibiting anisotropic properties and different crystallographic orientations. That is, these grains react differently to the applied macroscopic stress. This gives rise to the building of complex mechanical interactions which have a large influence on the overall polycrystal behavior and on the associated distributions of stress and strain in the different grains. An important feature is the development of strain and stress heterogeneities inside the grains which are absolutely essential for allowing the material to deform according to the set of associated mechanical equations that have to be fulfilled (stress equilibrium, continuity of displacements, local anisotropic constitutive relation, and boundary conditions). The stress heterogeneity can be characterized by the stress localization tensor $\mathbf{B}$ defined with 
$\sigma_{\mathrm{ij}}=B_{\mathrm{ijk} 1} \bar{\sigma}_{\mathrm{kl}}$

so that $\mathbf{B}$ can be interpreted as the "ratio" between local stress $\boldsymbol{\sigma}$ and macroscopic stress $\overline{\boldsymbol{\sigma}}$.

The difficulty of any micromechanical approach is to find this localization tensor. Once they are known, local stress and strain can be determined, as well as the effective behavior of the considered material. Obviously, B depends on the anisotropy of the local behavior and on the microstructure of the specimen which may be complex.

The self-consistent (SC) model [25,26] is often applied for estimating polycrystals' mechanical properties [27], and also for interpreting diffraction data [28]. As all other mean-field homogenization methods, this model is based on a statistical description of the microstructure of the polycrystalline aggregate. Since the SC model provides the exact response of perfectly disordered microstructures, it is a good candidate for polycrystal modeling, combining accuracy and relative simplicity. Complete expressions for the effective stiffness and localization tensors can be found in Ref. [29] for general anisotropic situations.

In the following, the coefficients $\widetilde{C}_{\mathrm{ijk} 1}$ will be estimated for different microstructures (crystallographic textures) using the SC model. The direction-dependent (anisotropic) Young's modulus can be calculated as follows:

$\frac{1}{E(\mathbf{n})}=n_{\mathrm{i}} n_{\mathrm{j}} n_{\mathrm{k}} n_{1} \widetilde{S}_{\mathrm{ijkl}}$

where $\mathbf{n}$ is a unit vector in a given tensile direction for which the Young's modulus is calculated. Similarly, the anisotropic Poisson's ratio can be estimated by

$v(\mathbf{n}, \mathbf{t})=-\frac{t_{\mathrm{i}} t_{\mathrm{j}} n_{\mathrm{k}} n_{1} \widetilde{S}_{\mathrm{ijk} 1}}{n_{\mathrm{i}} n_{\mathrm{j}} n_{\mathrm{k}} n_{1} \widetilde{S}_{\mathrm{ijk} 1}}$

with $\mathbf{t}$ a unit vector along a direction perpendicular to the tensile direction $\mathbf{n}$.

\section{Fabrication and microstructure of thin films}

Gold films were produced by physical vapor deposition (PVD) on Kapton ${ }^{\circledR}$ and GaAs substrates. Non-textured gold films have been deposited by sequenced magnetron sputtering. The base pressure of the growth chamber was $10^{-5} \mathrm{~Pa}$ while the working pressure during film growth was approximately $10^{-2} \mathrm{~Pa}$. Deposition was carried out at room temperature (RT) with an $\mathrm{Ar}^{+}$-ion-gun sputtering beam at $1 \mathrm{keV}$. The total thickness was measured using a Dektak II-a surface profilometer system to be $500 \pm$ $10 \mathrm{~nm}$. $\left\{\begin{array}{llll}1 & 1 & 1\end{array}\right\}$ fiber-textured gold films have been deposited by continuous ion-beam sputtering. The base pressure of the growth chamber was $7 \times 10^{-5} \mathrm{~Pa}$ while the working pressure during film growth was approximately $10^{-2} \mathrm{~Pa}$. Deposition was carried out at $\mathrm{RT}$ with an $\mathrm{Ar}^{+}$-ion-gun sputtering beam at $1.2 \mathrm{keV}$. Total thickness was measured to be $700 \pm 10 \mathrm{~nm}$.

Structural features of the as-deposited $\mathrm{Au}$ thin films were characterized thanks to XRD and transmission electron microscopy (TEM). XRD texture investigations were carried out using a Seifert XRD 3003 diffractometer operating at $40 \mathrm{kV}$ and $30 \mathrm{~mA}$, and using a $\mathrm{Cu}$ X-ray source $(\lambda=0.15418 \mathrm{~nm})$. The incident beam was collimated using a $0.5 \mathrm{~mm}$ diameter optical fiber and focused on the samples mounted on a four-circle goniometer including Eulerian cradle for $\Psi$ tilting (declination angle between the scattering vector $\mathbf{q}$ and the direction normal to the film surface $\left(S_{3}\right)$, see Fig. 1). Fig. 2 shows great differences between the $\Psi$ scans obtained for the $\left\{\begin{array}{lll}1 & 1 & 1\}\end{array}\right.$ planes family of the two samples. The film obtained by ion-beam sputtering (full line) is characterized by sharp peaks observed at $\Psi=0^{\circ}$ (along the direction normal to the surface) and at $\Psi=70.5^{\circ}$. The degree of scatter of this texture is quantified by the full width at half maximum (FWHM) of the peaks, $\sim 10^{\circ}$, revealing a relatively sharp $\left\{\begin{array}{llll}1 & 1 & 1\end{array}\right\}$ texture for ion-beam sputtered films. In contrast, the film obtained by sequenced magnetron sputtering (dotted lines) is characterized by an almost constant intensity,

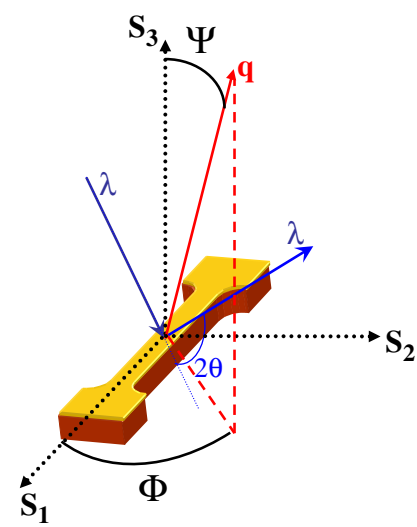

Fig. 1. Description of the diffraction angles $\Phi$ and $\Psi$. $\left(S_{1}, S_{2}, S_{3}\right)$ is the sample reference frame, which is used throughout this study. We have also represented a dog-bone specimen that is used for the tensile tests.

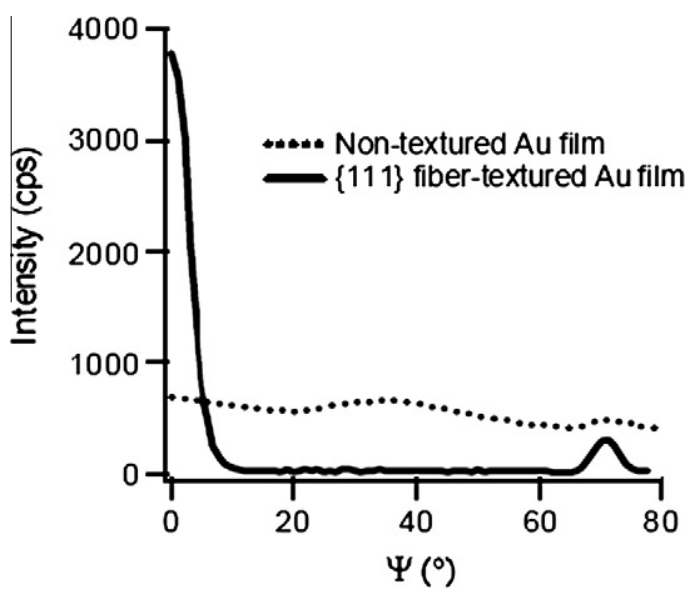

Fig. 2. $\Psi$ scan obtained for the $\left\{\begin{array}{llll}1 & 1 & 1\end{array}\right\}$ planes family of gold thin films deposited on polyimide substrate. The $\left\{\begin{array}{llll}1 & 1 & 1\end{array}\right\}$ textured gold film (full line) is characterized by sharp peaks observed at $\Psi=0^{\circ}$ and at $\Psi=70.5^{\circ}$. These are characteristics of a strong $\left\{\begin{array}{lll}1 & 1 & 1\end{array}\right\}$ texture. In contrast, the nontextured gold film (dotted lines) is characterized by an intensity showing small variations when $\Psi$ is varied. 
characteristic of a random (or isotropic) texture. It should be noted that no significant variations in intensity were found when azimuthal angle $\Phi$ was changed (rotational symmetry around the direction normal to the sample surface, see Fig. 1) for both films, revealing thus the transverse isotropy around the film normal. The textures (not shown here) obtained experimentally on GaAs substrates were similar, in agreement with TEM investigations. Fig. 3 shows

\section{(a)}

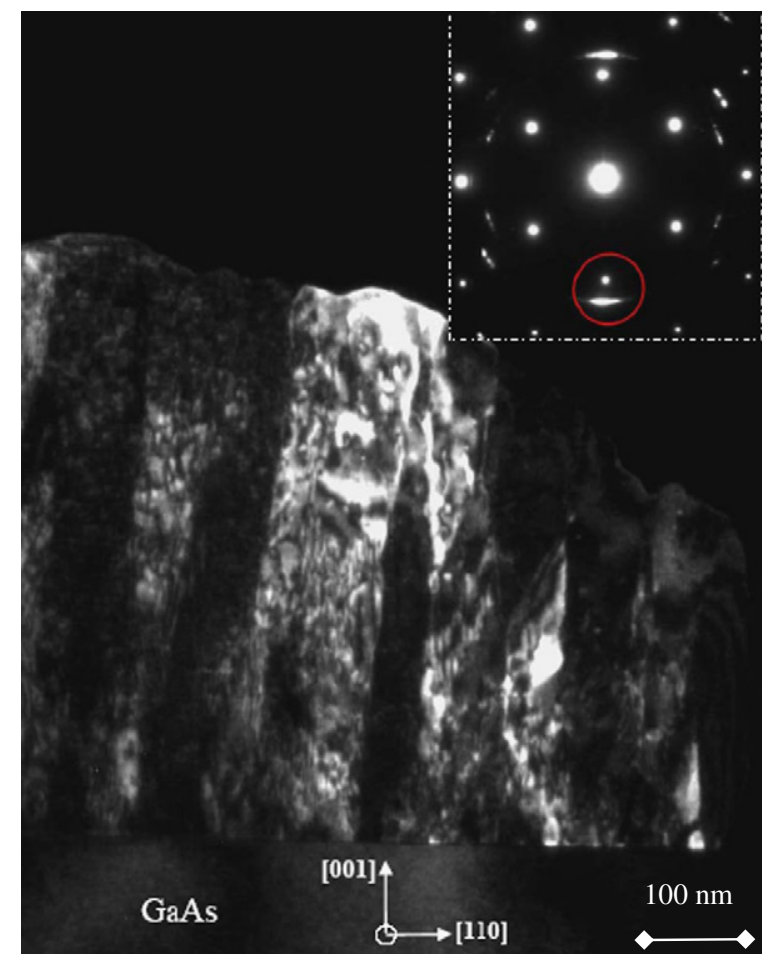

(b)

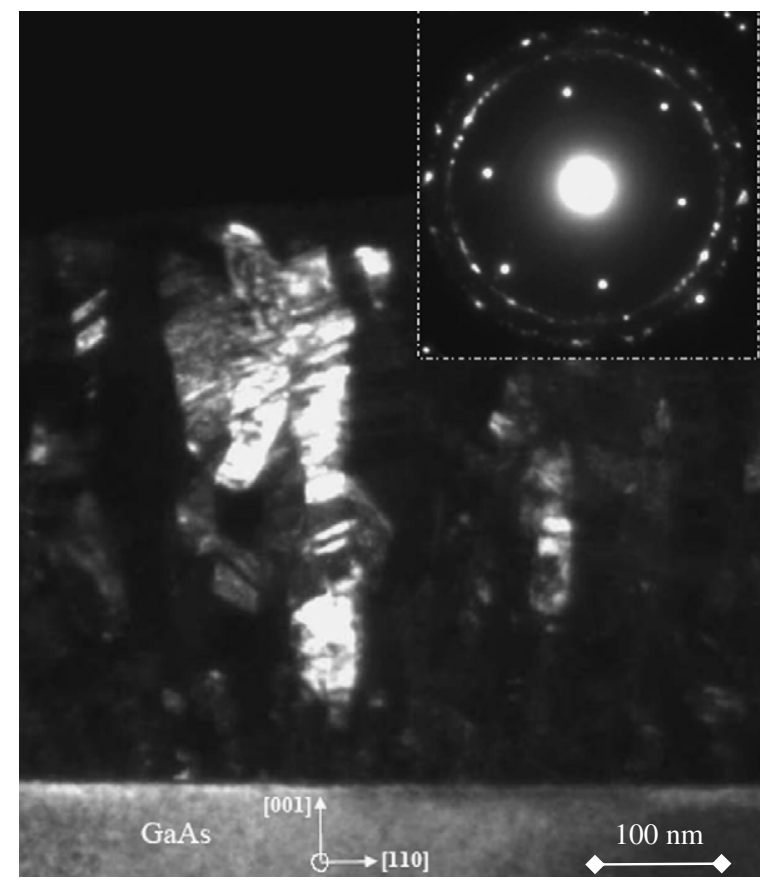

Fig. 3. TEM cross-section view and electronic diffraction diagram for (a) the $\left\{\begin{array}{lll}1 & 1 & 1\end{array}\right\}$-fiber-textured gold films and (b) the non-textured gold films deposited on GaAs.
TEM cross-sectional views of the $\left\{\begin{array}{lll}1 & 1 & 1\end{array}\right\}$ fiber-textured (Fig. 3a) and non-textured (Fig. 3b) gold films respectively, deposited on GaAs. The microstructure was found to be dense for both films, with grains elongated along the growth direction. The mean grain diameter was found to be around $50 \mathrm{~nm}$, i.e. large enough to neglect size effects on elastic properties. Moreover, electron diffraction diagrams show the degree of scatter of the texture for the two films (inset of Fig. 3a). It is $\sim 15^{\circ}$ for the $\left\{\begin{array}{lll}1 & 1 & 1\end{array}\right\}$ textured film, in relatively good agreement with the results obtained from XRD, while a complete diffraction ring is observed for the non-textured ones confirming then the random distribution of crystallographic grain orientation evidenced by XRD.

\section{Experimental characterization of gold thin film elastic behavior}

\subsection{X-ray diffraction and in situ tensile testing}

\subsubsection{Theoretical background and experimental set-up}

Elastic behavior of supported thin films can be studied by coupling in situ tensile tests and XRD. Intragranular strains are determined from the relative Bragg peak position shifts, while the overall stresses applied to the filmsubstrate composite are determined from a load cell fixed to one jaw of the microtensile tester [30-34]. For a purely elastic response, following Eqs. (2) and (5), the local strain $\varepsilon_{\mathrm{ij}}(\mathbf{x})$ at any position $\mathbf{x}$ inside the material is given by

$\varepsilon_{\mathrm{ij}}(\mathbf{x})=S_{\mathrm{ijkl}}(\mathbf{x})\left[B_{\mathrm{klmn}}(\mathbf{x}) \bar{\sigma}_{\mathrm{mn}}\right]$

where the stress localization tensor $\mathbf{B}$ is here estimated by means of the SC model. In this study, the relative shift of diffraction peak position is measured with respect to line positions at the macroscopically unloaded state, since this allows for an accurate study of the mechanical behavior without ad hoc assumption regarding the residual stress distribution generated by the deposition process. The socalled "lattice strain" $\varepsilon_{\Phi, \Psi}^{h k l}$ associated to the peak position shift is a direct measurement of the mean axial elastic strain

$\varepsilon_{\Phi, \Psi}^{h k l}=n_{\mathrm{i}} n_{\mathrm{j}}\left\langle\varepsilon_{\mathrm{ij}}\right\rangle_{\Omega}=n_{\mathrm{i}} n_{\mathrm{j}}\left[\left\langle S_{\mathrm{ijkl}}(\mathbf{x}) B_{\mathrm{klmn}}(\mathbf{x})\right\rangle_{\Omega} \bar{\sigma}_{m n}\right]$

with $\mathbf{n}$ a unit vector parallel to the scattering vector, and $\langle\cdot\rangle_{\Omega}$ denoting the average over the diffracting volume $\Omega$ associated to the $\{h k l\}$ diffracting planes $[35,36]$. The components $\left\langle S_{\mathrm{ijkl}}(\mathbf{x}) B_{\mathrm{klmn}}(\mathbf{x})\right\rangle_{\Omega}$ provide general expressions for the X-ray elastic constants (XEC). Eq. (9) recovers the classical $\sin ^{2} \Psi$ law for macroscopically isotropic materials (linear relationship between lattice strain and $\sin ^{2} \Psi$ [37]) given here for a biaxial macroscopic stress state generally used for thin films:

$$
\begin{aligned}
\varepsilon_{\Phi, \Psi}^{h k l}= & \frac{1}{2} S_{2}^{h k l}\left(\bar{\sigma}_{11} \cos ^{2} \Phi+\bar{\sigma}_{22} \sin ^{2} \Phi\right) \cdot \sin ^{2} \Psi \\
& +S_{1}^{h k l}\left(\bar{\sigma}_{11}+\bar{\sigma}_{22}\right)
\end{aligned}
$$

where $\frac{1}{2} S_{2}^{h k l}$ and $S_{1}^{h k l}$ are $h k l$-dependent XECs of the macroscopically isotropic material [23]. 
Using a four-circle goniometer, it is possible to characterize the elastic behavior for almost any orientation of $\mathbf{n}$ (see Fig. 1). Then, a least-square fitting procedure is adopted to adjust results of the SC model to experimental data and to determine single-crystal and subsequent macroscopic elastic constants, the crystallographic texture of the film being known.

The tensile loads were applied to dog-bone specimens (films adherent to Kapton ${ }^{\circledR}$ substrates) by means of a $200 \mathrm{~N}$ Deben $^{\mathrm{TM}}$ tensile module. This tensile tester is equipped with a $20 \mathrm{~N}$ load cell enabling the force measurement with a precision of $0.2 \mathrm{~N}$ ( $1 \%$ of full scale range). XRD measurements were performed using a four-circle goniometer. We analyzed five independent plane families:

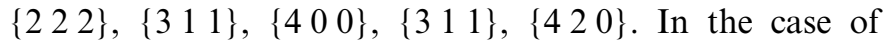
non-textured film, the measurements have been performed for the longitudinal direction $\left(\Phi=0^{\circ}\right)$ and for eight different $\Psi$ values arbitrary chosen between $0^{\circ}$ and $66^{\circ}$ (for each plane family). In the case of $\left\{\begin{array}{lll}1 & 1 & 1\end{array}\right\}$ textured film, the measurements have been performed for the longitudinal direction $\left(\Phi=0^{\circ}\right)$ and in the pole directions (nine different $\Psi$ values ranging from $0^{\circ}$ to $75^{\circ}$ ).

Obviously, substrate elastic constants have to be known to determine how total uniaxial stress localizes in the $\mathrm{Au}$ films. We used $E_{\mathrm{s}}=5.17 \pm 0.03 \mathrm{GPa}$ and $v_{\mathrm{s}}=0.312 \pm$ 0.010 values, which have been measured experimentally using the same Deben machine [18]. The Poisson's ratio of the substrate is clearly different from the one of gold films leading to in-plane biaxial applied stress state in the film $\left(\bar{\sigma}_{11} \neq \bar{\sigma}_{22}\right)$.

\subsubsection{Results}

4.1.2.1. Non-textured film. We have systematically observed a linear relationship between lattice strain and applied load, showing that the films behave elastically (not shown). The measured lattice strains for $\left\{\begin{array}{lll}2 & 2 & 2\end{array}\right\}$ and $\left\{\begin{array}{lll}4 & 0 & 0\end{array}\right\}$ plane families are shown in Fig. 4a and b, respectively, as a function of $\sin ^{2} \Psi$, for three external loads. From the two graphs, it is possible to characterize the local anisotropy since strain is $h k l$-dependent. The $\left\{\begin{array}{lll}40 & 0\end{array}\right\}$ planes deform elastically much more than the $\left\{\begin{array}{lll}2 & 2 & 2\end{array}\right\}$ planes (strain is about twice as large for $\{400\}$ as for $\{222\}$ under the same loading conditions). Indeed, these two plane families show extreme elastic behaviors for fcc materials giving the bound values, the elastic modulus associated with $\left\{\begin{array}{lll}4 & 0 & 0\end{array}\right\}$ plane family being the lowest. Nonetheless, the linear relationship between lattice strain and $\sin ^{2} \Psi$ is characteristic of isotropic macroscopic elasticity that is verified here for a random texture (see Eq. (10)). From the whole experimental data, we can evaluate the macroscopic elastic constants, assuming a macroscopic isotropic behavior [23]. Knowing $\bar{\sigma}_{11}$ and $\bar{\sigma}_{22}$, it is possible to determine $\frac{1}{2} S_{2}^{h k l}$ and $S_{1}^{h k l}$ from the slope and the intercept of the linear fit of $\varepsilon_{\phi, \Psi}^{h k l}$ as a function of $\sin ^{2} \Psi$, as shown in Eq. (10). Therefore the $h k l$-dependent elastic constants can be plotted as a function of orientation parameter $\Gamma(h k l)$, which is defined by
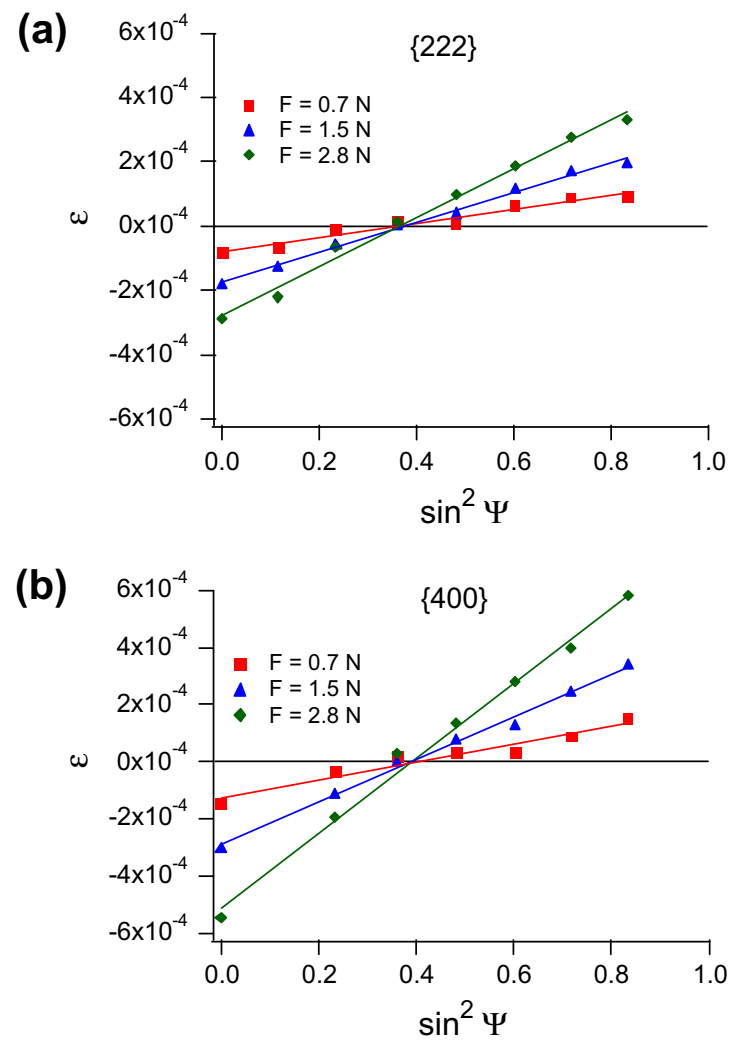

Fig. 4. Experimental X-ray lattice strains for (a) $\left\{\begin{array}{lll}2 & 2 & 2\end{array}\right\}$ and (b) $\left\{\begin{array}{lll}4 & 0 & 0\end{array}\right\}$ plane families as a function of $\sin ^{2} \Psi$, for the non-textured gold film.

$\Gamma(h k l)=\left(h^{2} k^{2}+h^{2} l^{2}+k^{2} l^{2}\right) /\left(h^{2}+k^{2}+l^{2}\right)^{2}$

Then, the mechanical elastic constants $(E$ and $v)$ are obtained from the values of $\frac{1}{2} S_{2}^{h k l}$ and $S_{1}^{h k l}$ for $\Gamma(h k l)=0.2$ (average over all orientations).

In this way, no elastic grain interaction model is required to determine mechanical elastic constants of thin films showing isotropic texture. Experimentally determined values of the stiffness components $\widetilde{C}_{\mathrm{ij}}$, the Young's modulus, and the Poisson's ratio, are reported in Table 1. They will be discussed in Section 5.

4.1.2.2. $\left\{\begin{array}{lll}1 & 1 & 1\end{array}\right\}$ fiber-textured film. As for non-textured film, we have systematically observed a linear relationship between lattice strain and applied load, showing that the films behave elastically. The measured strains for all loaded states are plotted as a function of $\sin ^{2} \Psi$ in Fig. 5. The film anisotropic elastic behavior is obvious on a $\varepsilon-\sin ^{2} \Psi$ plot with an obtained non-linearity regardless of the loaded state. In order to calculate single-crystal elastic compliances of textured gold films, the SC model is adjusted to experimental data using a least-square process. The minimization of the difference between measured lattice strains and calculated ones was made for the overall measured lattice strain (for all different $\Psi$ and/or $h k l$ ). The three single-crystal elastic constants can be obtained as fitting parameters in a least-square minimization of the difference chi-square $\left(\chi^{2}\right)$. 
Table 1

Calculated and measured macroscopic elastic constants.

\begin{tabular}{|c|c|c|c|c|c|c|c|c|c|}
\hline & $\tilde{C_{11}}(\mathrm{GPa})$ & $\widetilde{C}_{13}(\mathrm{GPa})$ & $\widetilde{C}_{33}(\mathrm{GPa})$ & $\widetilde{C}_{44}(\mathrm{GPa})$ & $E_{\|}(\mathrm{GPa})$ & $E_{\perp}(\mathrm{GPa})$ & $v_{12}$ & $v_{13}$ & $E_{\mathrm{r}}^{\mathrm{appr}}(\mathrm{GPa})$ \\
\hline \multicolumn{10}{|l|}{ Calculated } \\
\hline$\left\{\begin{array}{lll}1 & 1 & 1\end{array}\right\}$ fiber-textured & 213 & 145 & 221 & 23 & 91 & 117 & 0.53 & 0.30 & 130 \\
\hline Isotropic & 208 & 152 & 208 & 28 & 80 & 80 & 0.42 & 0.42 & 98 \\
\hline \multicolumn{10}{|l|}{ Experimental } \\
\hline \multicolumn{10}{|l|}{ XRD } \\
\hline$\left\{\begin{array}{lll}1 & 1 & 1\end{array}\right\}$ fiber-textured & $225 \pm 10$ & $160 \pm 10$ & $235 \pm 10$ & $24 \pm 2$ & $87 \pm 5$ & $106 \pm 5$ & $0.57 \pm 0.03$ & $0.32 \pm 0.03$ & $118 \pm 8$ \\
\hline Isotropic & $236 \pm 10$ & $178 \pm 10$ & $236 \pm 10$ & $29 \pm 2$ & $83 \pm 5$ & $83 \pm 5$ & $0.43 \pm 0.03$ & $0.43 \pm 0.03$ & $102 \pm 8$ \\
\hline \multicolumn{10}{|l|}{ Nanoindentation } \\
\hline$\left\{\begin{array}{lll}1 & 1 & 1\end{array}\right\}$ fiber-textured & & & & & & & & & $105-120$ \\
\hline Isotropic & & & & & & & & & $70-95$ \\
\hline \multicolumn{10}{|l|}{ BLS } \\
\hline$\left\{\begin{array}{lll}1 & 1 & 1\end{array}\right\}$ fiber-textured & $190 \pm 10$ & $142 \pm 10$ & $227 \pm 10$ & $18.5 \pm 1$ & & & & & \\
\hline Isotropic & $214 \pm 10$ & $168 \pm 10$ & $214 \pm 10$ & $23 \pm 1$ & & & & & \\
\hline
\end{tabular}

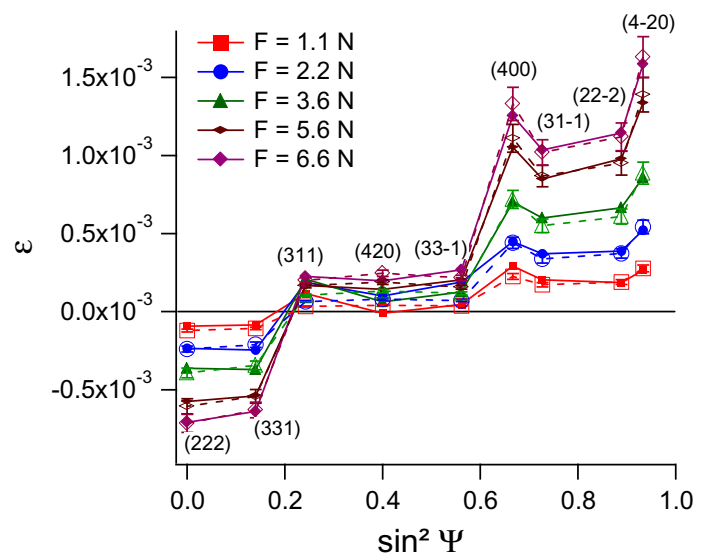

Fig. 5. Experimental (full lines and closed symbols) and theoretical (dotted lines and open symbols) lattice strains as a function of $\sin ^{2} \Psi$, for the $\left\{\begin{array}{lll}1 & 1 & 1\end{array}\right\}$ fiber-textured gold thin film. The theoretical points are plotted using thin-film single-crystal stiffnesses $C_{11}, C_{12}$, and $C_{44}$ obtained from the least-square process, using the self-consistent model. The segmented lines are only guides for the eye.

Fig. 5 shows that a rather good agreement is obtained simultaneously for all the loaded states. This fitting procedure yields the single-crystal elastic constants of the studied film, and subsequently the macroscopic elastic constants as shown in Table 1. The texture effect on the elastic constants is quite clear, as discussed extensively in Section 5. An estimated error for each of the single-crystal elastic constants can be calculated from the parameters of the fitting results, i.e., chi-square, degree of freedom, number of points. The incertitude on the elastic coefficients has been determined from the estimates of fitting errors which are the standard deviation of the fit coefficients. These values were determined to be around $10 \%$ for the whole raw data. The fitting procedure has also been verified using only one part of the raw data, that is for only 3 or 4 applied forces instead of 5 . In all cases, the fitting procedure converges with outputs within a $10 \%$ error.

The single-crystal elastic constants of gold films were extracted using the least-squares procedure refine- ment: $\quad C_{11}=204.8 \pm 15.0 \mathrm{GPa}, \quad C_{12}=175.4 \pm 10.0 \mathrm{GPa}$ and $C_{44}=42.0 \pm 3.0 \mathrm{GPa}$. These values are close to bulk ones $\left(C_{11}=192.9 \mathrm{GPa}, C_{12}=163.8 \mathrm{GPa}\right.$ and $C_{44}=41.5$ GPa) [38]. In fact, as for non-textured gold film, no size effect is expected in the grain-size range studied here (about $50 \mathrm{~nm})$ [39].

\subsection{Nanoindentation}

Instrumented indentation allows monitoring the penetration of a tip as a function of load. The test consists of loading up to a maximum value $P_{\max }$ (a hold period may be programmed) and unloading to zero. The tips are categorized into sharp and blunt depending on their geometry. Sharp ones (used here) are generally a three-faced Berkovich tip, allowing for a better definition of the contact area $A_{\mathrm{c}}$ as compared to a Vickers four-faced one. The so-called reduced modulus $E_{\mathrm{r}}$ can be extracted from the load-penetration curves employing the well-known "Oliver and Pharr" method referred after their respective authors [40].

Nevertheless, this method has several limitations. One major assumption is that only elastic recovery happens while unloading, which might not be strictly the case for very slight indents [41]. Secondly, the methodology was derived from the solution of elastic contact problems while prior to unloading the contact conditions involve plastic deformation [42]. Thirdly, the material around the contact may exhibit substantial pile-up or sink-in, the projected contact area being then either underestimated or overestimated and yielding errors in the indentation modulus values. Moreover, on studying a coated substrate, the response has to be investigated as a function of penetration depth in order to extract the sole film response. Depending on the applied load amplitude, the probe is either local (weak load) or global (strong load). For low loads, the elastic fields extend to only a few grains in thin films while it widely propagates to the substrate for high loads.

For this study, nanoindentation experiments were conducted at RT using a NHT nanoindenter from CSM 
Instruments, equipped with a Berkovich diamond indenter loaded to maximum load (between 0.2 and $10 \mathrm{mN}$ ) in $30 \mathrm{~s}$, maintained for $30 \mathrm{~s}$ and unloaded in $30 \mathrm{~s}$. The calibration procedure suggested by Oliver and Pharr [40] was used to correct for the load-frame compliance of the apparatus and the imperfect shape of the indenter tip.

Fig. 6 is a plot of the indentation reduced moduli of the $\left\{\begin{array}{lll}1 & 1 & 1\end{array}\right\}$-fiber-textured and non-textured $\mathrm{Au}$ films on GaAs substrate as a function of $h_{\mathrm{c}} / t$ ratio, where $h_{\mathrm{c}}$ is the contact penetration between the indenter and the film, and $t$ its thickness. The measured elastic moduli are affected by the substrate response. As $h_{\mathrm{c}} / t$ ratio increases, the response changes from film-dominated to substrate-dominated. This is expected since the elastic field is a long-range field that extends into the substrate on increasing the load. The rate of increase scales with the mismatch in moduli between the film and the substrate. At large penetrations (at $h_{\mathrm{c}} / t$ over 0.35 ), a relatively good convergence of the responses on both systems is obtained, i.e. penetration depths for which the substrate contribution is predominant (reduced modulus about $125 \mathrm{GPa}$ ). Instead, the reduced moduli of the films are extrapolated at small depth $\left(h_{\mathrm{c}} / t<0.1\right)$ and the obtained values are around 105-120 GPa and 70-95 GPa for the $\left\{\begin{array}{llll}1 & 1 & 1\end{array}\right\}$-fiber-textured and non-textured specimens respectively. It should be noted here that for the small penetrations, the measurement dispersion is larger for the nontextured gold films. For these specimens, the grains' crystallographic orientations are randomly distributed, and thus the tip probes different grains along different crystallographic directions, revealing the local elastic anisotropy. Instead, in the $\left\{\begin{array}{lll}1 & 1 & 1\end{array}\right\}$ textured gold films, all grains are oriented with a $\left\langle\begin{array}{llll}1 & 1 & 1\end{array}\right\rangle$ direction nearly along the loading axis (normal direction to the film surface), giving rise to more limited data spread. At low contact depth the surface roughness, which is a few nanometers for the two films deposited on GaAs, is also expected to account for some scatter although the difference between specimens could not be easily quantified.

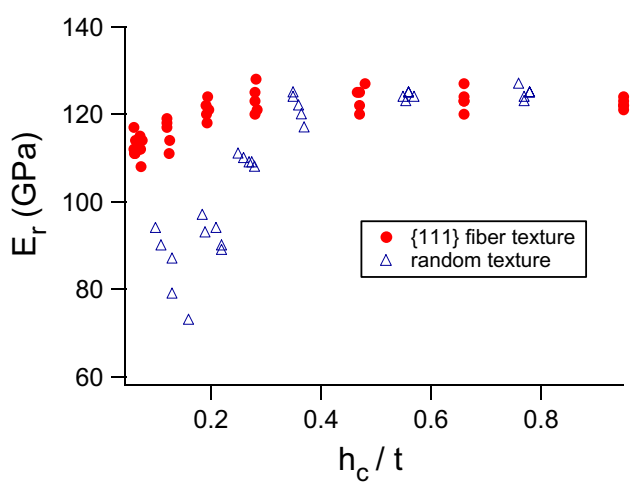

Fig. 6. Indentation reduced moduli of the $\left\{\begin{array}{lll}1 & 1 & 1\end{array}\right\}$-fiber-textured and nontextured $\mathrm{Au}$ films on GaAs substrate determined using the method of Oliver and Pharr, as a function of $h_{\mathrm{c}} / t$, where $h_{\mathrm{c}}$ is the contact penetration between the indenter and the materials and $t$ is the thickness of the films.

\subsection{Brillouin light scattering}

\subsubsection{Basics and experimental set-up}

Measurement of the whole set of constants is usually out of the reach of conventional static techniques, which can give information about directional elastic modulus. On the other hand, the use of acoustic techniques based on surface acoustic waves (SAWs) presents technical difficulties connected with the fabrication of the acoustical delay line. In addition, one has to consider that in the frequency range commonly used, the large values of the acoustic wavelength, compared to the film thickness, impose a careful consideration of the effect of the substrate on the propagation of the SAW [43].

During the last twenty years, BLS has proved to be very efficient for achieving a complete elastic characterization of thin films and multilayered structures [44]. In a BLS experiment, a monochromatic light beam is used to probe and to reveal acoustic phonons which are naturally present in the medium under investigation. The power spectrum of these phonons is mapped out from frequency analysis of the light scattered within a solid angle. Because of the wave vector conservation in the phonon-photon interaction, the wavelength of the revealed elastic waves is of the same order of magnitude as that of light. This means that the wavelength is much larger than the interatomic distances, so that the material can be described as a continuum within an effective-medium approach.

The BLS spectra were taken in air at RT, with typical acquisition times of $1-2 \mathrm{~h}$. The light source was an $\mathrm{Ar}^{+}$ laser on a single mode of the $514.5 \mathrm{~nm}$ line. $300 \mathrm{~mW}$ of p-polarized light was focused on the surface of the sample and the scattered light was analyzed by means of a Sandercok-type $3+3$ pass tandem Fabry-Perot interferometer. Here, we used the backscattering interaction geometry, so that the value of the wave vector of the probed surface acoustic waves is fixed experimentally to the value $Q_{\|}=2 k \sin \theta$, where $k$ denotes the optical wave vector in air and $\theta$ the incidence angle of the light beam.

\subsubsection{Results}

For nearly opaque films with thicknesses lower or around the acoustic wavelength $(0.3-0.4 \mu \mathrm{m})$, supported by substrates with acoustic phase velocities higher than that of the films (slow film/fast substrate), such as a gold film on a GaAs substrate, we can only observe the surface acoustic waves with a sagittal polarization (Fig. 7): the Rayleigh wave (RW) and the so-called Sesawa guided waves $\left(S_{1}-S_{n}\right)$ [45], the corresponding phase velocities being measured. These last modes are dispersive, so that measurements of the acoustic wave frequencies are usually performed for different angles of incidence (i.e. different values of the in-plane wave vector) that enable the determination of the elastic constants. In the present case, four of the five effective elastic constants, namely $\widetilde{C}_{11}, \widetilde{C}_{13}, \widetilde{C}_{33}$ and $\widetilde{C}_{44}$, influence the Rayleigh and Sezawa modes, so that they can be evaluated by a best-fit procedure of the experimental 
(a)

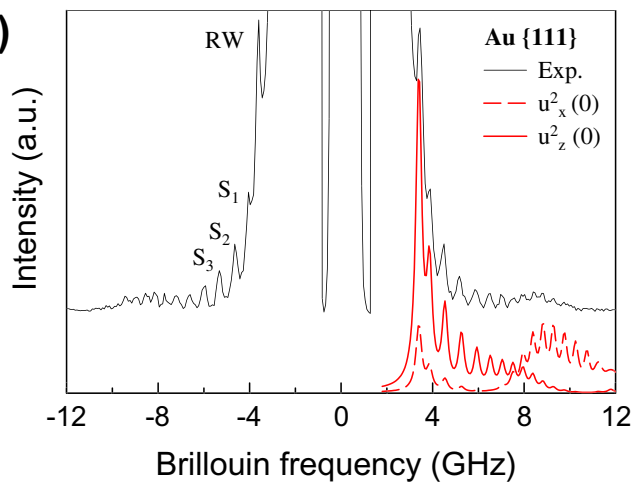

(b)

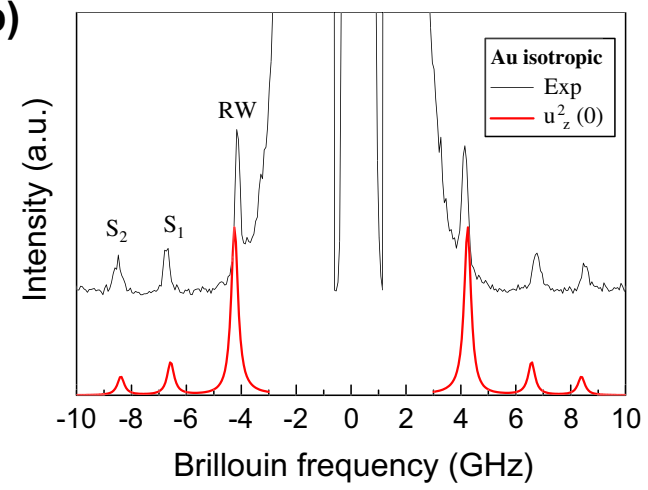

Fig. 7. Brillouin spectrum (a) of the gold layer with $\left\{\begin{array}{lll}1 & 1 & 1\end{array}\right\}$-fiber texture and (b) of the isotropic gold layer on a GaAs substrate. The incident angle is $\theta=65^{\circ}$. RW denotes the Rayleigh surface wave, $S_{i}$ the $i$ th Sesawa guided waves. Below we have indicated the calculated power spectrum at the free surface of the displacement components $\left\langle u_{z}^{2}(0)\right\rangle$ (vertical, associated to the ripple scattering mechanism) and $\left\langle u_{x}^{2}(0)\right\rangle$ (longitudinal).

velocities to the calculated dispersion curves. The fifth elastic constant $\widetilde{C}_{66}$ can be determined from measurements of the phase velocity of shear horizontal modes (Love modes) but are not observed here because of their low scattering efficiency. Obviously, calculation of Young's modulus and Poisson's ratio is then not possible.

Non-textured films can be considered as macroscopically isotropic since the crystallites are randomly distributed, as shown in Section 3. Thus, only the two effective elastic constants, $\widetilde{C}_{11}$ and $\widetilde{C}_{44}=\left(\widetilde{C}_{11}-\widetilde{C}_{12}\right) / 2$, have to be measured. $\widetilde{C}_{12}$ can be calculated afterwards, assuming a global isotropy.

By taking into account only the ripple mechanism for the scattered intensity by the surface acoustic waves, the experimental spectra for the non-textured film are well fitted. In the case of textured films, the agreement is only qualitative except for $\widetilde{C}_{44}$ effective constant that is related to the Rayleigh surface wave. The contribution of the $\mathrm{Au} / \mathrm{GaAs}$ interface and of the photoelastic coupling should be considered for a better description of the intensity at higher frequencies (more than $8 \mathrm{GHz}$ ). The adjustment of surface mode positions leads to effective elastic constant values shown in Table 1. Experimental values show differences of effective elastic properties between the non-textured and the $\left\{\begin{array}{lll}1 & 1 & 1\end{array}\right\}$-textured gold films. $\widetilde{C}_{44}$ decreases drastically $(20 \%)$ from non-textured to textured films.
Experiments show also a decrease of $\widetilde{C}_{13}$ and an increase of $\widetilde{C}_{11}$ and $\widetilde{C}_{33}$, and these are discussed in more detail in the next section.

\section{Discussion}

The study encompasses measurements of elastic constants performed both by static (in situ tensile tests, nanoindentation) and dynamic methods (BLS). While the difference between adiabatic and isothermal elastic constants is expected to be small compared to usual experimental uncertainties [46], the aim of the present work was to check whether the uncertainties are small enough for measuring texture effect on the effective elastic constants. Since different kinds of elastic constants (local or effective stiffnesses, Young's modulus, Poisson's ratio) can be determined with the used experimental techniques (static/dynamic, local/global), it is imperative to know how the texture influences those elastic constants.

To illustrate the effects of texture on the effective elastic constants, we generated numerically $\left\{\begin{array}{llll}1 & 1 & 1\end{array}\right\}$ fiber textures with various texture dispersions (Gaussian dispersion around texture axis from $0^{\circ}$ to $120^{\circ}$ ). Here, the texture dispersion is given by the FWHM of the Gaussian distribution. Calculations of effective $\widetilde{C}_{\mathrm{ij}}$ were made using the SC model and bulk $\mathrm{Au}$ single-crystal elastic constants $C_{\mathrm{ij}}$ $\left(C_{11}=192.9 \mathrm{GPa}, \quad C_{12}=163.8 \mathrm{GPa}, \quad C_{44}=41.5 \mathrm{GPa}\right)$. Fig. 8 shows the evolution of $\widetilde{C}_{\mathrm{ij}}$ as a function of texture dispersion, the effect of which can be observed for FWHM ranging from $10^{\circ}$ to $90^{\circ}$. When dispersion is equal to $120^{\circ}$, the effective elastic behavior is almost isotropic, with $\widetilde{C}_{11}=\widetilde{C}_{33}, \widetilde{C}_{12}=\widetilde{C}_{13}, \widetilde{C}_{44}=\widetilde{C}_{66}$. It should be noted here that the obtained values for large texture dispersions $\left(>100^{\circ}\right)$ are very close to those obtained with a random texture (not shown here). In fact, texture with dispersion lower than $10^{\circ}$ can be considered as strong (nearly perfect fiber texture), while it is nearly isotropic when dispersion is higher than $100^{\circ}$. The effective constant most affected by the texture change is $\widetilde{C}_{44}$, for which the relative difference between a strong $\left\{\begin{array}{llll}1 & 1 & 1\end{array}\right\}$ fiber texture and an isotropic one is about $24 \%$. This difference is confirmed experimentally by BLS as shown in Section 4. Experimental and theoretical values agree relatively well (Table 1), evidencing difference of effective elastic properties between the nontextured and the $\left\{\begin{array}{llll}1 & 1 & 1\end{array}\right\}$-textured gold films. $\widetilde{C}_{44}$ is determined to decrease drastically both experimentally and theoretically by about $20 \%$ from non-textured to textured films. Moreover, both experiments and model show similar trends with a decrease for $\widetilde{C}_{13}$ and an increase for $\widetilde{C}_{33}$ on changing the texture from isotropic to $\left\{\begin{array}{lll}1 & 1 & 1\end{array}\right\}$. Instead, experiments and model show reverse trends for $\widetilde{C}_{11}$. The latter result is more surprising; however, it should be kept in mind that the theoretically determined difference for this constant is quite low and expected to be within $2.5 \%$.

The model can be further used to determine the in-plane and out-of-plane Young's moduli $E_{\|}$, and $E_{\perp}$ as a function 
(a)

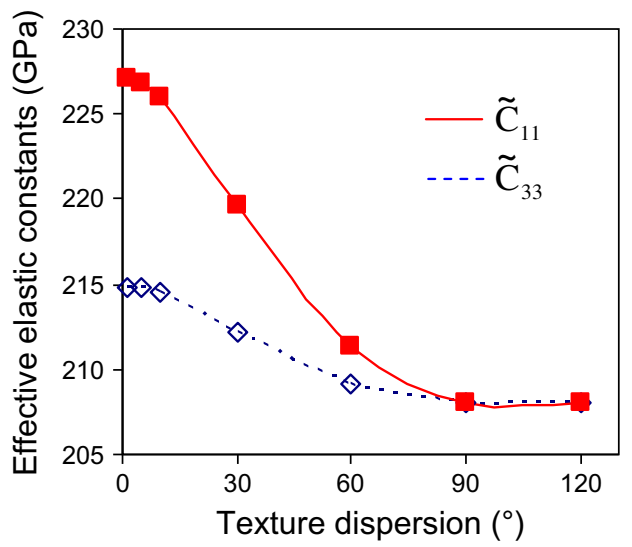

(b)

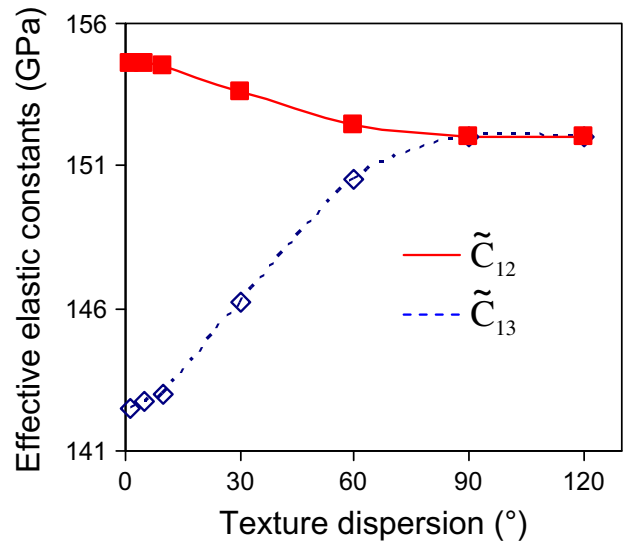

(c)

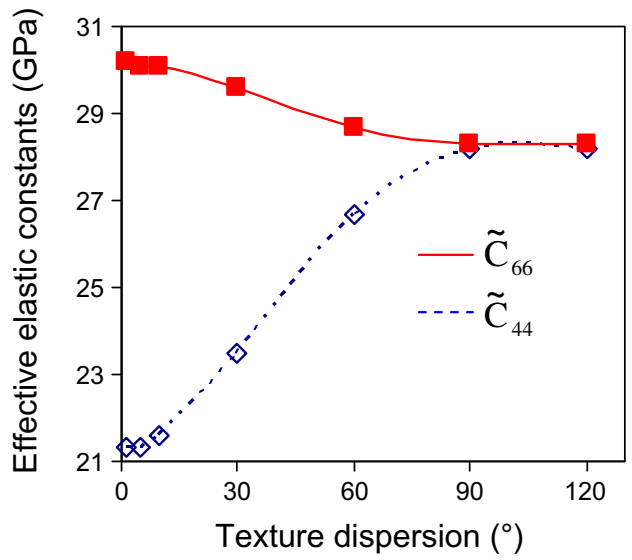

Fig. 8. Evolution of $\widetilde{C}_{\mathrm{ij}}$ elastic constants as a function of texture dispersion

of dispersion, as shown in Fig. 9a. The influence of texture is expected to be about $10 \%$ and $30 \%$ for $E_{\|}$and $E_{\perp}$ respectively, according to the SC model. Regarding Poisson's ratio (Fig. 9b), $v_{12}$ (in-plane) decreases from 0.52 to 0.43 while $v_{13}$ (perpendicular) increases from 0.30 to 0.43 , so that a strong effect is also expected. This behavior is further illustrated in Fig. 10, which shows two-dimensional (2D) parametric surfaces of theoretical Young's modulus (Fig. 10a) and Poisson's ratio (Fig. 10b) for perfect $\left\{\begin{array}{lll}1 & 1 & 1\end{array}\right\}$-fiber-textured and non-textured gold films (the two extreme cases) in the sample reference frame $S$ $\left(\mathrm{S}_{1}, S_{2}, S_{3}\right)$. Since the films are transversely isotropic (in (a)

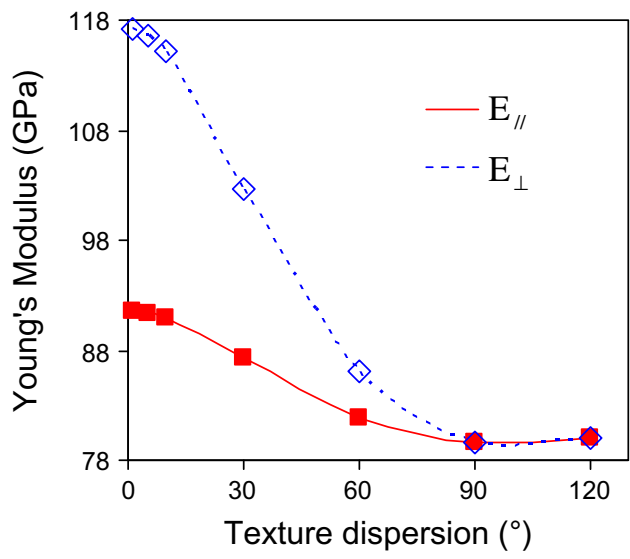

(b)

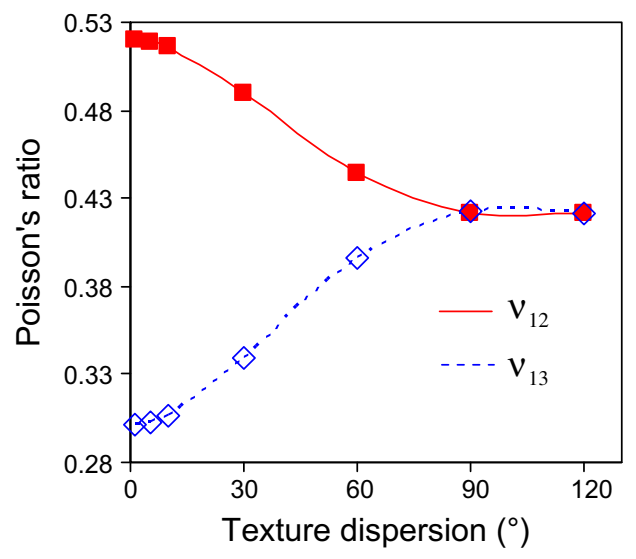

Fig. 9. Evolution of (a) in-plane Young's modulus $E_{\|}$and perpendicular Young's modulus $E_{\perp}$ and (b) Poisson's ratios $v_{12}$ (in-plane) and $v_{13}$ (perpendicular).

the plane $\left.\left(S_{1}, S_{2}\right)\right)$, the whole anisotropic behavior can be illustrated in the plane $\left(S_{1}, S_{3}\right)$ (or $\left(S_{2}, S_{3}\right)$ ). Obviously, non-textured gold films are macroscopically isotropic, which is characterized by a circle for Young's modulus and Poisson's ratio. In contrast, $\left\{\begin{array}{lll}1 & 1 & 1\end{array}\right\}$-fiber-textured gold film is anisotropic, and the representations in Fig. 10a and $\mathrm{b}$ depart significantly from a circle. It should be noted here that $E_{\|}$and $v_{12}$ are located along $S_{1}$, while $E_{\perp}$ and $v_{13}$ are located along $S_{3}$.

The influence of crystallographic texture on Young's modulus and Poisson's ratio has been quantified experimentally by studying gold thin films with tensile testing and nanoindentation. As expected by calculations, a strong anisotropy effect (more than 20\%) has been detected for $v_{12}, v_{13}$ and $E_{\perp}$ using XRD and in situ tensile tests, as shown in Table 1. The effect on $E_{\|}$is smaller than expected (about $5 \%$ instead of $12 \%$ theoretically). This could result from a softer macroscopic anisotropy for the $\left\{\begin{array}{llll}1 & 1 & 1\end{array}\right\}$-textured film as compared to the theoretical one. 2D parametric surfaces of experimental Young's modulus (Fig. 10a) and Poisson's ratio (Fig. 10b) of $\left\{\begin{array}{llll}1 & 1 & 1\end{array}\right\}$-fiber-textured and non-textured gold films are shown and compared to the theoretical ones. Obviously, the macroscopic anisotropy determined experimentally for the $\left\{\begin{array}{lll}1 & 1 & 1\end{array}\right\}$-fiber texture seems to be less pronounced than the one calculated 

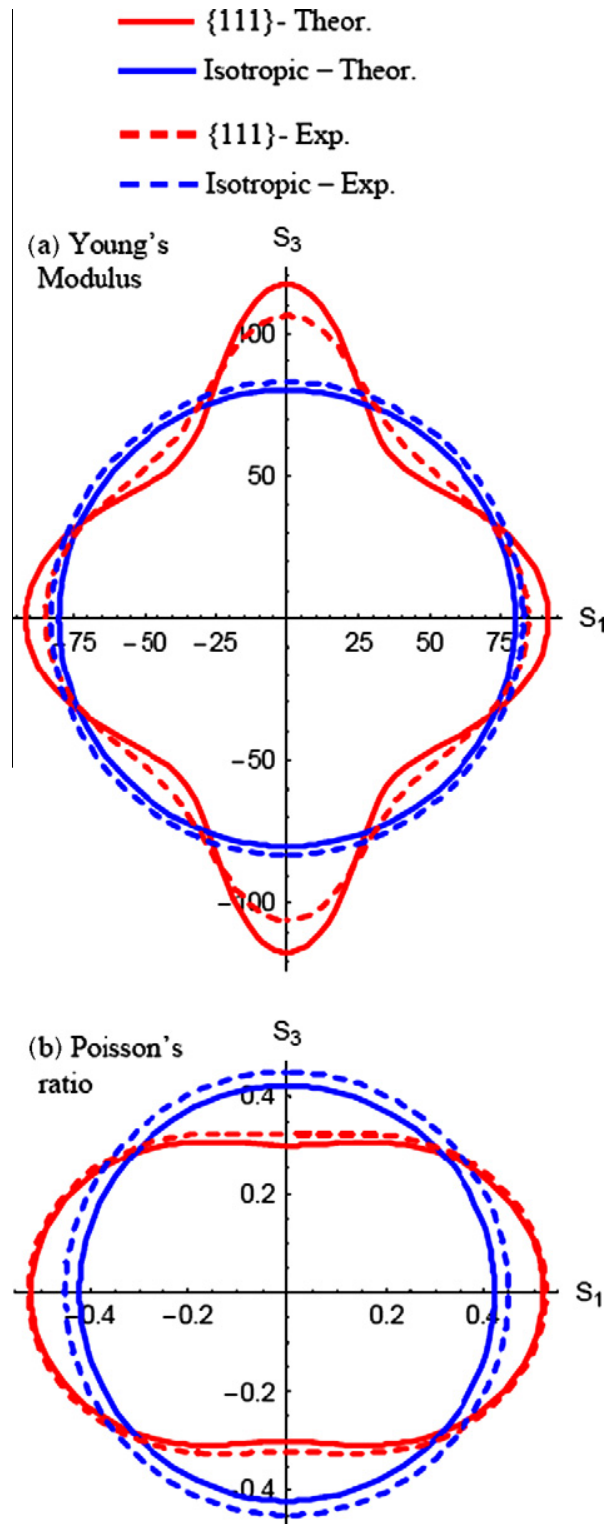

Fig. 10. Two-dimensional parametric surfaces of experimental and theoretical (a) Young's modulus and (b) Poisson's ratio, of perfect $\left\{\begin{array}{lll}1 & 1 & 1\end{array}\right\}$-fiber-textured and non-textured gold films.

for a perfect $\left\{\begin{array}{lll}1 & 1 & 1\end{array}\right\}$-fiber texture. Of course, the actual texture of the film is not a perfect fiber, and is characterized by a dispersion (about $10^{\circ}$ in our case) that tends to smooth out the macroscopic elastic anisotropy.

Using nanoindentation, we found a relative difference (about $25 \%$ ) between the indentation reduced moduli of the two films that can be explained by the texture effect. Indeed, during an indentation test the main contribution to the elastic response is along the loading axis; it is thus expected to be sensitive to the global elastic anisotropy [47]. As shown in Fig. 10, the out-of-plane Young's modulus $E_{\perp}$ decreases from $118 \mathrm{GPa}$ to $80 \mathrm{GPa}$ when the texture dispersion increases from $0^{\circ}$ (perfect $\left\{\begin{array}{llll}1 & 1 & 1\end{array}\right\}$ fiber texture) to $120^{\circ}$ (isotropic texture), while the Poisson ratio $v_{13}$ varies from 0.3 to 0.43 . An approximated reduced modulus $E_{\mathrm{r}}^{\text {appr }}$ can then be calculated, considering the orientation depen- dent modulus along loading axis and the in-plane Poisson ratio, as described in Ziegenhain et al. [48], with

$E_{\mathrm{r}}^{\mathrm{appr}}=\frac{E_{\perp}}{1-v_{13}^{2}}$

It is determined to increase from $98 \mathrm{GPa}$ (non-textured) to $130 \mathrm{GPa}\left(\begin{array}{lll}1 & 1 & 1\end{array}\right\}$ fiber texture) in relatively good agreement with the observed trend. Obviously, this approach adopted below for the overall measurements is an approximation of the true behavior, and overestimates the elastic anisotropy effects during nanoindentation tests [48]. Anisotropy effect on reduced modulus can be predicted using Vlassak and Nix charts [47,49] and is determined to increase from $98 \mathrm{GPa}$ to only $104 \mathrm{GPa}$.

The calculations of reduced modulus using Eq. (12) with the elastic constants determined from the in situ tensile test technique, are shown in Table 1 . We found $E_{\mathrm{r}}^{\mathrm{appr}}=$ $118 \mathrm{GPa}$ for the textured film and $102 \mathrm{GPa}$ for the non-textured ones. While the reduced modulus of the non-textured film is not significantly changed, the $\left\{\begin{array}{lll}1 & 1 & 1\end{array}\right\}$ textured film one is lower. As discussed before, the dispersion or the fiber texture tends to smooth out the macroscopic elastic anisotropy, which is taken into account in this case.

In order to illustrate the texture effect on elastic response, Fig. 11 shows the relative difference between $\left\{\begin{array}{lll}1 & 1 & 1\end{array}\right\}$-fiber texture and isotropic texture macroscopic elastic constants as a function of the Zener anisotropy index $\left(A=2 C_{44} /\left(C_{11}-C_{12}\right)\right)$, for a few commonly studied fcc materials (for which $\left\{\begin{array}{llll}1 & 1 & 1\end{array}\right\}$-texture is often encountered). Obviously, the relative difference globally increases with single-crystal elastic anisotropy. Except for $\widetilde{C}_{11}$, the texture effect should be easily detected for materials with Zener anisotropy index larger than 2. Indeed, if this is the case, the difference for $E_{\|}$is larger than $10 \%$ and can be captured when applying "classical" tensile testing of thin film. The texture effect is much more manifest $(>20 \%)$ for $\widetilde{C}_{44}$ (which may be detected by acoustic techniques and

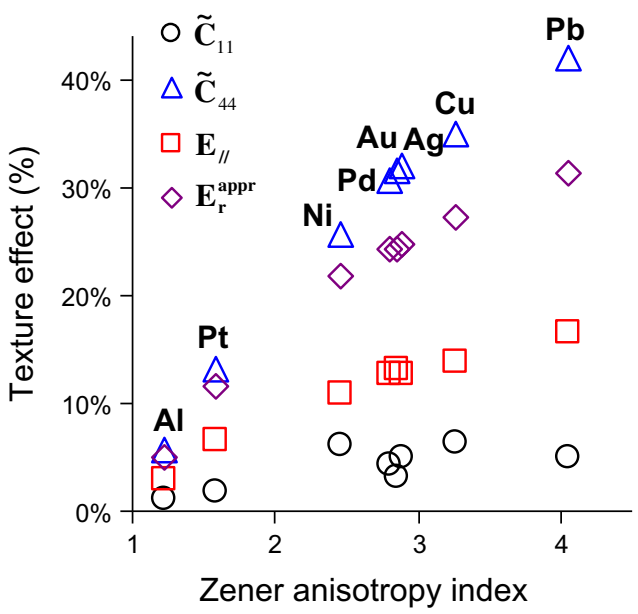

Fig. 11. Relative texture effect (i.e. relative variation of elastic constants between the $\left\{\begin{array}{llll}1 & 1 & 1\end{array}\right\}$-fiber texture and the isotropic texture of a given material) on some macroscopic elastic constants, as a function of the Zener anisotropy index, for several fcc materials. 
BLS), and also for approximated reduced modulus $E_{\mathrm{r}}^{\text {appr }}$ (which may be detected by nanoindentation and XRD), even if it provides an overestimation of the true effect detected by nanoindentation. In contrast, for nearly isotropic materials such as Al, the texture effect should be small as compared to measurement uncertainties.

\section{Concluding remarks}

Elastic properties of non-textured and $\left\{\begin{array}{lll}1 & 1 & 1\end{array}\right\}$-fiber-textured gold thin films were investigated by some characterization techniques: in situ tensile testing under XRD, nanoindentation and BLS. These widely used methods reveal quite differently the elastic anisotropy since both physical background and probe characteristics vary considerably. The experiments presented here allowed the two different textured thin films to be distinguished. It has been shown that the correlation between all obtained results can be hardly noticeable without a proper modeling of the response in view of the microstructure.

The diffractive method allowing for a selective assessment of crystallographic planes is very powerful to study both the local and global anisotropies in polycrystalline materials and offers a complete picture of the mechanical response. The precision of this picture depends upon the resolution of the X-ray beam, which is improved using synchrotron radiation. Nanoindentation test permits determining only one macroscopic elastic constant (indentation reduced modulus) along the loading axis (generally normal to thin film surface), while BLS allows determining several effective stiffnesses and hence detecting the elastic macroscopic anisotropy. Experimental results were confronted to micromechanical calculations of effective elastic constants, taking into account the actual microstructure. We have shown that the texture effect on the macroscopic elastic constants can be detected by those three techniques, but are demonstrated differently with relatively good agreement with the proposed modeling approach. The presented results show that XRD, BLS and nanoindentation can capture texture effects on elastic constants measurements for materials with Zener anisotropy index larger than 2. Conversely, the actual texture of a given specimen should be taken into account for a proper analysis of elastic constants measurements using those three experimental techniques.

\section{References}

[1] Freund LB, Suresh S. Thin film materials: stress, defect formation, and surface evolution. Cambridge: University Press; 2003.

[2] Von Blanckenhagen B, Arzt E, Gumbsch P. Acta Mater 2004;52(3):773-84.

[3] Choi Y, Suresh S. Acta Mater 2002;50:1881.

[4] Balk TJ, Dehm G, Arzt E. Acta Mater 2003;51:4471.

[5] Choi D, Nix WD. Acta Mater 2006;54:679.

[6] Majdoub MS, Sharma P, Cagin T. Phys Rev B 2008;77:125424.

[7] Chen X, Vlassak J. J Mater Res 2001;16:2974-82.

[8] Florando JN, Nix WD. J Mech Phys Solids 2004;53:619-38.

[9] Xiang Y, Chen X, Tsui TY, Jang J-I, Vlassak JJ. J Mater Res 2006;21(2):386-95.
[10] Walter ME, Schneider AS, Wübben T, Richter G, Arzt E. Strain 2008;45:238-48.

[11] Huang H, Spaepen F. Acta Mater 2000;48:3251.

[12] Dirras GF, Djemia P, Roussigné Y, Jackson KM. Mater Sci Eng A 2004;387-389:302-6.

[13] Tanei H, Nakamura N, Ogi H, Hirao M, Ikeda R. Phys Rev Lett 2008;100:016804.

[14] Nakamura N, Ogi H, Hirao M. Phys Rev B 2008;77:245416.

[15] Rossignol C, Perrin B, Bonello B, Djemia P, Moch P, Hurdequint H. Phys Rev B 2004;70:094102.

[16] Decremps F, Belliard L, Perrin B, Gauthier M. Phys Rev Lett 2008;100:035502.

[17] Djemia Ph, Roussigne Y, Dirras GF, Jackson KM. J Appl Phys 2004;95:2324-30.

[18] Faurie D, Renault P -O, Le Bourhis E, Goudeau Ph. J Appl Phys 2005;98:093511.

[19] Hurley DC, Geiss RH, Kopycinska-Müller M, Müller J, Read DT, Wright JE, et al. J Mater Res 2005;20:1186.

[20] Thompson CV, Carel R. J Mech Phys Solids 1996;44:657.

[21] Wu HP, Wu LZ, He QL, Zhang PW, Du SY. Appl Surf Sci 2008;254:5517

[22] Wu HP, Wu LZ, Du SY. J Appl Phys 2008;103:083546.

[23] Faurie D, Renault P-O, Le Bourhis E, Goudeau Ph. Acta Mater 2006;54:4503-13.

[24] Zhang JM, Zhang Y, Xu KW, Ji V. Physica B 2008;403:3379-83.

[25] Hershey AV. J Appl Mech 1954;21:236-40.

[26] Kröner E. Z Phys 1958;151:504-18.

[27] Lebensohn RA, Liu Y, Ponte Castaneda P. Acta Mater 2004;52:5347-61.

[28] Faurie D, Castelnau O, Brenner R, Renault P-O, Le Bourhis E, Goudeau Ph. J Appl Cryst 2009;42:1073-84.

[29] Brenner R, Castelnau O, Badea L. Proc R Soc Lond A 2004;460:3589-612.

[30] Renault P-O, Le Bourhis E, Villain P, Goudeau P, Badawi KF, Faurie D. Appl Phys Lett 2003;83:473-5.

[31] Faurie D, Renault P-O, Villain P, Le Bourhis E, Goudeau P, Badawi F. Thin Solid Films 2004;469:201-5.

[32] Faurie D, Castelnau O, Renault P-O, Brenner R, Le Bourhis E, Goudeau P, et al. Appl Phys Lett 2006;89:061911.

[33] Geandier G, Teat S, Renault P-O, Le Bourhis E, Lamongie B, Goudeau P. J Appl Cryst 2008;41:1076-88.

[34] Gruber PA, Solenthaler C, Arzt E, Spolenak R. Acta Mater 2008;56:1876-89.

[35] Letouzé N, Brenner R, Castelnau O, Bechade JL. Scripta Mater 2002;47:595

[36] Castelnau O, Geandier G, Renault P-O, Goudeau P, Le Bourhis E. Thin Solid Films 2007;516:320-4.

[37] Noyan IC, Cohen JB. Residual stress measurement by diffraction and interpretation. New York: Springer; 1987.

[38] Smithells JC. Metals reference book. 5th ed. London: Butterworths; 1976.

[39] Schiotz J, Vegge T, Di Tolle FD, Jacobsen KW. Phys Rev B 1999;60:11971.

[40] Oliver WC, Pharr GM. J Mater Res 1992;7:1564.

[41] Le Bourhis E, Patriarche G. Prog Cryst Growth Char Mater 2003;47:1.

[42] Le Bourhis E. Vacuum 2008;82:1353-9.

[43] Coufal H, Meyer K, Grygier RK, de Vries M, Jenrich D, Hess P. Appl Phys A 1994;59:83.

[44] Nizzoli F, Sandercock JR, Horton GK, Maradudin AA, editors. Dynamical properties of solids. North Holland: Elsevier; 1990. p. 281-335.

[45] Djemia P, Ganot F, Moch P, Branger V, Goudeau P. J Appl Phys 2001;90:756-62.

[46] Ledbetter HM, Naimon ER. J Phys Chem Ref Data 1974;3:897.

[47] Vlassak JJ, Nix WD. J Mech Phys Solids 1994;42:1223-45.

[48] Ziegenhain G, Urbassek HM, Hartmaier A. J Appl Phys 2010;107:061807.

[49] Vlassak JJ, Nix WD. Philos Mag A 1993;67:1045. 